\title{
MODEL PROBABILITAS PENGGUNA JALAN TERHADAP TARIF TOL SOLO - NGAWI (STUDI KASUS : KARTASURA - SRAGEN)
}

\author{
Dewi Handayani ${ }^{1}$, Jessica Rotua V Lubis $^{2}$, dan Lydia Novitriana Nurhidayati ${ }^{3}$ \\ ${ }^{\text {I} P r o g r a m ~ S t u d i ~ T e k n i k ~ S i p i l, ~ U n i v e r s i t a s ~ S e b e l a s ~ M a r e t, ~ J l . ~ I r . ~ S u t a m i ~} 36$ A Surakarta \\ Email:dewihandayani9@yahoo.com \\ ${ }^{2}$ Program Studi Teknik Sipil, Universitas Sebelas Maret, Jl. Ir. Sutami 36 A Surakarta \\ Email: rotuajessica@gmail.com \\ ${ }^{3}$ Program Studi Teknik Sipil, Universitas Sebelas Maret, Jl. Ir. Sutami 36 A Surakarta \\ Email: lydiahidayati@yahoo.com
}

\begin{abstract}
One of mega toll road project which is implemented by the government is Trans Jawa Toll project that consist of nine segments and one of the segment is Solo-Ngawi segment. As the Solo-Ngawi toll project is being developed, fee and travel time are very important. Therefore, the objective of research is to find out the probability model of road passagers whom will use toll road by the scenarios of toll fee and time which is given. Primary data was obtained by distributing stated preference questionnaire to road passagers who were passing on the artery road in Kartasura - Sragen. Survey form was grouped into 2: form 1 containing data of respondent characteristic and form 2 containing respondents' choice over 9 scenarios which consists 2 factors : fee toll from Willingness To Pay (WTP) analysis and travel time. Each of the atributs are the different between toll road and non toll road. Then, the data obtained would be analyzed the linier regression utility function using binary logit and probit model to know the comparative of the passagers road probability value. The result is similar probability value between logit and probit model. The biggest probability value occurs when the toll and non toll fee difference is Rp. 21.000 and the toll and non toll travel time difference is 75 minutes. The lowest probability value occurs when the toll and non toll fee difference is Rp. 38.500 and the toll and non toll travel time difference is 51 minutes.
\end{abstract}

Keywords: willingness to pay, binomial logit, binomial probit, stated preference

\begin{abstract}
ABSTRAK
Salah satu proyek mega jalan tol yang dicanangkan pemerintah adalah Proyek jalan Tol Trans Jawa yang terdiri dari sembilan ruas dan salah satunya adalah ruas Solo - Ngawi. Sejalan dengan pembangunan Proyek jalan Tol Solo - Ngawi, maka faktor tarif jalan tol dan waktu tempuh sangat diperhitungkan. Oleh karena itu, tujuan penelitian ini adalah untuk mengetahui model probabilitas pengguna jalan dalam memilih jalan tol berdasarkan tarif dan waktu tempuh. Data primer diperoleh dengan menyebarkan kuisioner stated preference kepada pengguna kendaraan pribadi beroda empat di ruas jalan arteri Kartasura - Sragen. Formulir survei dikelompokkan menjadi 2 bentuk formulir, yaitu formulir 1 berisi data karakteristik responden dan formulir 2 berisi pilihan responden terhadap 9 skenario yang diperoleh dari 2 faktor: tarif berdasarkan Willingness To Pay (WTP) dan waktu tempuh. Masing-masing atribut merupakan selisih dalam menggunakan jalan tol dan jalan non tol. Selanjutnya data yang diperoleh akan dianalisa fungsi utilitas regresi linier nya dengan model logit dan model probit untuk diketahui nilai perbandingan probabiltas pengguna. Sehingga hasil yang diperoleh merupakan nilai probabilitas yang hampir sama antara model logit dan probit. Probabilitas paling besar terjadi pada Skenario 1 dengan selisih tarif tol dan non tol Rp. 21.000 dan selisih waktu tempuh tol dan non tol 75 menit. Probabilitas paling kecil terjadi pada Skenario 9 dengan selilih tarif selisih tarif tol dan non tol Rp. 38.500 dan selisih waktu tempuh tol dan non tol 51 menit.
\end{abstract}

Kata kunci: willingness to pay, logit binomial, probit binomial, stated preference

\section{PENDAHULUAN}

Pengertian Jalan Tol yaitu jalan umum yang merupakan bagian dari sistem jaringan jalan yang penggunanya diwajibkan untuk membayar tarif yang telah ditentukan. Tujuan pembangunan jalan tol adalah menjadikan lalu lintas di daerah yang berkembang lancar, menunjang pertumbuhan ekonomi lewat peningkatan pelayanan distribusi jasa dan barang serta meringankan beban pemeritah dalam hal dana lewat partisipasi dari pengguna jalan. Proyek 
jalan Tol Trans Jawa merupakan salah satu mega proyek pembangunan jalan tol yang dicanangkan pemerintah. Tol Trans Jawa ini ditargetkan memiliki panjang sekitar kurang lebih $1000 \mathrm{~km}$ dan akan membentang sekaligus menyatu dengan sembilan ruas tol lain. Salah satu ruas tersebut adalah Jalan tol Kartasura - Sragen yang merupakan bagian dari Solo-Ngawi. Dengan adanya jalan tol Solo-Ngawi diharapkan dapat mempermudah akses transportasi bagi masyarakat yang akan berpergian ke Solo-Ngawi melalui Sragen. Sejalan dengan tujuan tersebut, maka faktor tariff jalan tol dan waktu tempuh merupakan faktor utama seseorang memilih menggunakan jalan tol. Oleh karena itu tujuan penelitian ini adalah untuk mengetahui nilai probabilitas pengguna jalan dalam menggunakan jalan tol sesuai skenario yang telah tersedia dengan model logit dan probit. Lokasi penelitian berada di Jalan Arteri KartasuraSragen, Jawa Tengah.

\section{TINJAUAN PUSTAKA DAN LANDASAN TEORI}

Penelitian tentang nilai probabilitas dalam menentukan pilihan dengan model logit dan probit telah dilakukan sebelumnya. Edy Rahardjo (2001) melakukan penelitian tentang perbandingan model probit dan logit dalam menghitung probabilitas pilihan menggunakan kendaraan pribadi dan angkutan umum, dan dari hasil penelitian disimpulkan bahwa model probit lebih akurat dalam menggambarkan perilaku pengguna kendaraan pribadi dan angkutan umum di Kota Semarang serta hasil perbedaan ke dua model probit dan logit sebesar 26,48\%.

\section{Jalan Tol}

Menurut undang-undang Republik Indonesia no. 38 tahun 2004 tentang Jalan, Jalan Tol adalah jalan umum yang merupakan bagian sistem jaringan jalan dan sebagai jalan nasional yang penggunaannya diwajibkan membayar tol. Sedangkan tol sendiri adalah sejumlah uang tertentu yang dibayarkan untuk pengguna jalan tol.

\section{Tarif Jalan Tol}

Prakoso (2011), mendefinisikan tarif sebagai harga atau biaya yang dikenakan sebagai kompensasi atas konsumsi suatu barang atau jasa. Sehingga, dalam jasa transportasi dapat diterapkan tarif untuk kompensasi atas konsumsi jasa transportasi.

\section{Teori Permintaan Transportasi}

Menurut Kanafani (1983), Permintaan akan jasa transportasi merupakan permintaan turunan (derived demand) akibat adanya permintaan lain dan bersifat murni sebagai suatu kebutuhan turunan. Ada 4 (empat) atribut yang harus tersedia untuk penyediaan transportasi penumpang yaitu: total waktu perjalanan, total biaya perjalanan, jadwal yang tepat dan kenyamanan

\section{Teori Willingness to Pay (WTP)}

Willingness to Pay (WTP) adalah ketersediaan pengguna untuk mengeluarkan imbalan atas barang atau jasa yang diterimanya. Pendekatan yang digunakan dalam analisis WTP didasarkan pada preferensi dan persepsi pengguna terhadap tarif dari barang atau jasa tersebut. (Briedert, 2005). Dalam permasalahan transportasi, WTP dipengaruhi oleh beberapa faktor yaitu: kualitas dan kuantitas jasa, utilitas pengguna terhadap jasa tersebut serta penghasilan pengguna.

\section{Metode Stated Preference}

Metode stated preference adalah metode yang menggunakan pernyataan seorang responden mengenai preferensi responden terhadap pilihan transportasi untuk mengestimasi fungsi utilitas (Kroes dan Sheldon, 1988). Metode Stated Preference secara luas juga banyak digunakan untuk penelitian mengenai perilaku perjalanan dan secara praktik untuk mengidentifikasi respon dalam memilih suatu situasi yang belum ada di pasar, dimana level pada artribut yang ditawarkan oleh pilihan yang ada dimodifikasi sedemikian rupa.

\section{Analisis Data Stated Preference}

Analisis data stated preference digunakan untuk mendapatkan nilai utilitas. Nilai utilitas diketahui dengan melakukan pengukuran terhadap atribut-atribut suatu produk yang diprediksikan memberikan kepuasan produk tersebut, sehingga berfungsi untuk merefleksikan pengaruh pilihan responden pada seluruh atribut yang termasuk dalam stated preference, dan model matematik yang diturunkan dari data stated preference akan mencerminkan 
hipotesa dari peneliti. Utilitas biasa didefenisikan sebagai kombinasi linier dari beberapa atribut dan variabel yang mempunyai bentuk seperti pada Persamaan (1) :

$$
U_{n}=a_{0}+a_{1} x_{1}+\cdots+a_{n} x_{n}
$$

Dengan Un $=$ utilitas pilihan $\mathrm{n}, \mathrm{a}_{0}, \ldots, \mathrm{a}_{\mathrm{n}}=$ parameter model dan $\mathrm{x}_{0}, \ldots, \mathrm{x}_{\mathrm{n}}=$ nilai atribut

\section{Model Logit Binomial}

M. Aris Supriyanto (2003) mengatakan model logit merupakan salah satu teknil model dalam menentukan komponen utiliti (probabilitas pemilihan). Persamaan model ini dapat dilihat pada Persamaan (2).

$$
P_{j t}=1-P_{j n t}=\frac{1}{1+e^{\left(U_{j t}-U_{j n t}\right)}}
$$

dengan $\mathrm{P}_{\mathrm{jt}}=$ probabilitas pemilihan jalan tol, $\mathrm{P}_{\mathrm{jnt}}=$ probabilitas pemilihan jalan non tol, $\mathrm{U}_{\mathrm{jt}}=$ utilitas pemilihan jalan tol, dan $\mathrm{U}_{\mathrm{jnt}}=$ Utilitas pemilihan jalan non tol.

\section{Model Probit Biner}

Model probit merupakan salah satu asumsi logis yang menunjukkan sejumlah permasalahan yang besar pada komponen variabel bebas (Ben Akiva dan Bolduc, 1996). Persamaan model ini dapat dilihat pada Persamaan (3).

$$
P_{n}(i)=\varphi\left(\frac{v_{i n}-v_{\text {in }}}{\sigma}\right)
$$

dengan $\mathrm{V}_{\mathrm{in}}-\mathrm{V}_{\mathrm{jn}}=$ fungsi utilitas pemilihan jalan tol, $\sigma=$ standar deviasi dan $\varphi=$ kumulatif distribusi normal

\section{Koefisien Determinasi}

Setiap model akan menghasilkan nilai R-kuadrat yang berbeda. Nilai R-kuadrat yang baik adalah yang mendekati 1 . R-kuadrat menunjukkan presentase dari total variasi variabel tak bebas yang terjelaskan oleh variasi dari variabelvariabel tak bebasnya. Besaran pseudo- $\mathrm{R}^{2}$, tidaklah benar-benar analog dengan $\mathrm{R}^{2}$ pada model regresi linier, ini karena model regresi linier sesuai dengan namanya adalah linier sedangkan model Multi Non Linier yang berbasis pada choice analysis adalah non linier. Pada kenyatannya nilai pseudo- $\mathrm{R}^{2}$ pada rentang 0,3 sampai 0,4 dapat dianalogikan dengan nilai $\mathrm{R}^{2}$ sebesar 0,6 sampai 0,8 .

\section{Nilai Chi-squared $\left(\mathbf{x}^{2}\right)$}

Pengujian Chi-squared merupakan uji ketetapan model serta kesesuaian data dan digunakan untuk menguji hipotesa nol (Ho). Persamaan ini dapat dilihat pada Persamaan (4)

$$
\chi_{\text {hitung }}=-2\{L(0)-L(\beta)\}
$$

dengan $\mathrm{L}(\beta)=$ nilai likelihood $(\mathrm{L})$ maksimum dan $\mathrm{L}(0)=$ nilai awal likelihood jika semua parameter adalah 0

\section{METODE PENELITIAN}

Lokasi penelitian dilaksanakan di ruas jalan arteri Kartasuro - Sragen. Ruas jalan tol Kartasura - Sragen yang memiliki total panjang 35,22 km berlokasi di lima kabupaten yaitu Kabupaten Boyolali, Kotamadya Surakarta, Kabupaten Karanganyar dan Kabupaten Sragen yang berada di Propinsi Jawa Tengah. Data-data yang diperlukan 
antara lain proyeksi Lalu Lintas Harian Rata-rata Tahun 2017 di link jalur rencana jalan tol, penentuan biaya perjalanan dari PT SNJ selaku badan usaha pembangunan jalan tol dan nilai ketetapan kecepatan kendaraan dari Peraturan No.15 Tahun 2005.

Tahapan penelitian yang pertama dilakukan adalah melakukan desain kuesioner berdasarkan data-data yang sudah diperoleh untuk menentukan skenario kuesioner. Setelah kuesioner ditentukan, kuesioner kemudian disebar kepada 385 responden berupa pengguna jalan arteri Kartasura-Sragen. Survei dilaksanakan dua kali yaitu pertama pilot survei sebagai penggambaran kondisi pada saat survei nantinya dan sebagai pengujian apakah kuesioner yang digunakan sudah layak atau tidak. Setelah survei pendahuluan dikatakan layak, baru dilaksanakan survei utama. Survei dilakukan untuk mendapatkan data primer. Setelah data primer didapat, dilakukan beberapa uji statistik, yaitu uji uji reabilitas dan uji validitas data untuk mengetahui nilai kebenaran data hasil kuesioner terhadap skenario serta membandingkan nilai tersebut dengan tabel $\mathrm{r}$. Kemudian menghitung besar nilai selisih utilitas pemilihan jalan tol dan jalan non tol dengan model dengan logit dan probit. Setelah nilai utilitas didapat, dilakukan pengujian untuk mengetahui hasil presentasi kesesuaian antara hasil survei dengan pilihan yang tersedia pada kuesioner dengan uji overall percentage. Kemudian melakukan uji chi-square digunakan untuk mengetahui apakah variabel-variabel yang terdapat dalam penelitian memiliki hubungan serta melakukan pengujian koefisien determinasi $\left(\mathrm{R}^{2}\right)$ guna mengukur besar kecilnya sumbangan/kontribusi perubahan variabel bebas terhadap perubahan variabel terikat yang di amati.

\section{Hasil Dan Pembahasan}

\section{Pengumpulan Data}

Pengumpulan data dalam penelitian ini dilaksanakan selama 14 hari yaitu pada tanggal 17 April 2017 - 30 April 2017 dengan mengambil sampel di lokasi penelitian yang telah ditentukan serta melakukan pilot survey selama 2 hari pada tanggal 7 April 2017 - 8 April 2017. Pada saat melaksanakan pilot survey, kuesioner dilaksanakan dengan skala Linkert variabel ordinal dengan 5 skala jawaban yaitu: pasti memilih jalan tol, mungkin memilih jalan tol, ragu-ragu, mungkin tidak memilih jalan tol, dan pasti tidak memilih jalan. Setelah peneliti mengolah data kuesioner, metode linkert tidak menghasilkan utilitas yang sesuai dengan syarat statistik. Sehingga peneliti kemudian mengubah metode linkert menjadi metode Discrete Choice dengan skala jawaban menjadi 2 buah yaitu: Ya (menggunakan jalan tol) dan Tidak (tidak menggunakan jalan tol).

\section{Deskripsi Data Responden}

Berdasarkan penyebaran kuisioner dari 385 pengguna jalan, karakteristik pengguna jalan berdasarkan jenis kelamin dapat dilihat pada Tabel 1.

Tabel 1. Jumlah Pengguna Jalan dengan Karakteristik Pengguna berdasarkan Jenis Kelamin

\begin{tabular}{lcc}
\hline Jenis Kelamin & Jumlah & Persentase \\
\hline Laki-laki & 328 & 85,12 \\
\hline Perempuan & 57 & 14,88 \\
\hline Jumlah & $\mathbf{3 8 5}$ & $\mathbf{1 0 0}$ \\
\hline
\end{tabular}

Berdasarkan penyebaran kuisioner dari 385 pengguna jalan, karakteristik pengguna jalan berdasarkan usia dapat dilihat pada Tabel 2 . 
Tabel 2. Jumlah Pengguna Jalan dengan Karakteristik Pengguna berdasarkan Usia

\begin{tabular}{lcc}
\hline Usia & Jumlah & Persentase \\
\hline $23-32$ & 93 & 24,28 \\
\hline $33-42$ & 89 & 23,24 \\
\hline $43-52$ & 112 & 29,24 \\
\hline $53-62$ & 78 & 19,84 \\
\hline $63-72$ & 13 & 3,4 \\
\hline Jumlah & $\mathbf{3 8 5}$ & $\mathbf{1 0 0}$ \\
\hline
\end{tabular}

Berdasarkan penyebaran kuisioner dari 385 pengguna jalan, karakteristik pengguna jalan berdasarkan pekerjaan dapat dilihat pada Tabel 3.

Tabel 3. Jumlah Pengguna Jalan dengan Karakteristik Pengguna berdasarkan Pekerjaan

\begin{tabular}{lll}
\hline Usia & Jumlah & Persentase \\
\hline Wiraswasta & 101 & 26,37 \\
\hline Karyawan Swasta & 116 & 30,29 \\
\hline PNS & 85 & 22,19 \\
\hline Pegawai BUMN & 37 & 9,14 \\
\hline Lainnya & & \\
\hline Jumlah & 46 & 12,01 \\
& & $\mathbf{1 0 0}$ \\
\hline
\end{tabular}

\section{Pengujian Kuesioner}

Sebelum peneliti menghitung nilai utilitas pemilihan jalan tol dengan model probit dan logit, peneliti terlebih dahulu menguji kuesioner dengan Uji Reabilitas dan Uji Validitas agar mengetahui tingkat kelayakan kuesioner sehingga menghasilkan data yang layak untuk dianalisis. Pengujian Reabilitas dan Validitas kuesioner dilakukan dengan Ms. Excel dan SPSS 20.0.

\section{Uji Reabilitas}


Dari hasil pengujian diperoleh nilai corrected item-total correlation berurutan dari skenario pertama adalah 0,312 ; 0,$605 ; 0,567 ; 0,525 ; 0,779 ; 0,716 ; 0,527 ; 0,780 ; 0,728$. Kuesioner dikatakan layak apabila nilai corrected itemtotal correlation pada masing-masing skenario $<$ nilai tabel $\mathrm{R}=0,1005$. Dapat dilihat bahwa nilai corrected itemtotal correlation pada seluruh skenario lebih besar daripada nilai $\mathrm{y}=0,1005$ sehingga dapat disimpulkan bahwa seluruh skenario sudah bagus dan kuesioner layak untuk disebar.

\section{Uji Validitas}

Dari hasil pengujian diperoleh nilai pada kolom total berurutan dari skenario pertama adalah 0,$408 ; 0,717 ; 0,672$; 0,$648 ; 0,840 ; 0,780 ; 0,655 ; 0,835 ; 0,787$. Kuesioner dikatakan layak apabila nilai total pada masing-masing skenario < nilai tabel $\mathrm{R}=0,1005$. Dapat dilihat bahwa nilai total seluruh skenario lebih besar daripada nilai $\mathrm{y}=$ 0,1005 sehingga dapat disimpulkan bahwa seluruh skenario sudah bagus dan kuesioner layak untuk disebar.

\section{Pemodelan Pemilihan Rute}

Sesuai dengan data yang telah diperoleh dari survei dapat dibuat persamaan untuk model logit binomial antara melalui jalan tol dan jalan non tol. Persamaan diperoleh dengan menggunakan model logit binomial selisih. Model diperoleh dengan menyusun probabilitas pilihan rute yang dipilh responden berdasarkan sembilan skenario. Selanjutnya dilakukan perhitungan dengan analisis regresi berganda yang diperoleh dari transformasi persamaan model logit dan probit binomial selisih. Analisis regresi berganda dilakukan dengan bantuan Ms.Excel dan SPSS 20.0 .

\section{Analisis Selisih Utilitas Jalan Tol}

Persamaan regresi yang dipakai untuk model utilitas Jalan Tol adalah seperti pada Persamaan (5) :

$U_{j t-j n t}=\alpha+\beta_{1(C j t-C j n t)}+\beta_{2(T j t-T j n t)}$

Dengan $U_{\mathrm{jt} \text {-jnt }}=$ model jalan tol terhadap jalan non tol, $\beta_{1}$ dan $\beta_{2}=$ koefisien, $C_{j t}=$ besar tarif yang berlaku pada jalan tol, $\mathrm{C}_{\mathrm{jnt}}=$ besar tarif yang berlaku pada jalan non tol, $\mathrm{T}_{\mathrm{jt}}=$ waktu perjalanan yang ditempuh saat melalui jalan tol, dan $\mathrm{T}_{\mathrm{jnt}}=$ waktu perjalanan yang ditempuh saat melalui jalan non tol.

\section{Perhitungan Variabel dan Uji Statistik dengan Model Logit}

Sebelum mencari nilai koefisien, dilakukan perhitungan yaitu selisih dari nilai kedua variabel yang digunakan. Nilai selisih tersebut adalah selisih antara Jalan Tol dan Jalan Non Tol. Sehingga didapat nilai variabel pembentuk logit binomial $\mathrm{U}_{\mathrm{Jt}-\mathrm{Jnt}}$. Nilai variabel disajikan seperti pada Tabel 4.

Tabel 4. Nilai Variabel Pembentuk Persamaan Logit Binomial Selisih $\mathrm{U}_{\mathrm{jt}}-\mathrm{U}_{\mathrm{jnt}}$

\begin{tabular}{lll}
\hline Skenario & Ca-Cb & Ta-Tb \\
\cline { 2 - 3 } & $\mathbf{X}_{\mathbf{1}}$ & $\mathbf{X}_{\mathbf{2}}$ \\
\hline 1 & 21000 & 40 \\
\hline 2 & 30000 & 49 \\
\hline 3 & 38500 & 54 \\
\hline
\end{tabular}




\begin{tabular}{lll}
\hline 4 & 21000 & 30 \\
\hline 5 & 30000 & 39 \\
\hline 6 & 38500 & 44 \\
\hline 7 & 21000 & 16 \\
\hline 8 & 30000 & 25 \\
\hline 9 & 38500 & 30
\end{tabular}

Melalui hasil rekapitulasi pada SPSS 20.0 untuk pemilihan rute Jalan Tol terhadap Jalan Non Tol, didapat nilai taksiran koefisien regresi modelnya, sehingga didapatkan model utilitas sebagai berikut :

$U_{j t-j n t}=3,105-0,185\left(C_{j t}-C_{j n t}\right)+0,052\left(T_{j t}-T_{j n t}\right)$

(6)

\section{Uji Statistik Chi-Square}

Dari hasil perhitungan pada program SPSS 20.0, didapatkan nilai Chi-Square sebesar 96,268 dengan nilai signifikansi sebesar 0,000 (<0,05) sehingga menolak Ho, yang menunjukkan bahwa penambahan variabel independen dapat memberikan pengaruh nyata terhadap model, atau dengan kata lain model dinyatakan fit.

\section{Uji Koefisien Determinasi}

Berdasarkan perhitungan menggunakan program SPSS 20.0, diketahui bahwa nilai Nagelkerke $R$ Square sebesar 0,287 . Nilai ini kemudia dianalogkan sehingga didapat nilai $\mathrm{R}^{2}$ sebesar 0,58 . Sehingga diketahui bahwa presentase pengaruh variabel tarif dan waktu pada model logit ialah sebesar 58\% sedangkan $42 \%$ dijelaskan oleh variabel lain.

\section{Uji Overall Percentage}

Berdasarkan pengujian dengan SPSS 20.0 didapatkan hasil Overall Percentage sebesar 72,5\%. Hasil Overall Percentage pada analisis ini masuk akal dan sesuai dengan syarat statistik. Peneliti juga melakukan pengujian dengan Ms. Excel dengan hasil $72.56 \%$.

\section{Perhitungan Variabel dan Uji Statistik dengan Model Probit}

Sebelum mencari nilai koefisien, dilakukan perhitungan yaitu selisih dari nilai kedua variabel yang digunakan. Nilai selisih tersebut adalah selisih antara Jalan Tol dan Jalan Non Tol. Sehingga didapat nilai variabel pembentuk probit

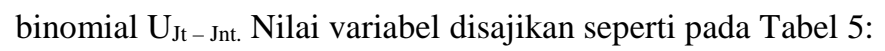

Tabel 5. Nilai Variabel Pembentuk Persamaan Probit Binomial Selisih $U_{j t}-U_{j n t}$

\begin{tabular}{lllll}
\hline Skenario & $\mathbf{C a}-\mathbf{C b}$ & Ta-Tb & Jawaban & Total \\
\cline { 2 - 5 } & $\mathbf{X}_{\mathbf{1}}$ & $\mathbf{X}_{\mathbf{2}}$ & $\mathbf{Y a}$ & Responden \\
\hline 1 & 21000 & 40 & 349 & 385
\end{tabular}




\begin{tabular}{lcccc}
\hline 2 & 30000 & 49 & 183 & 385 \\
\hline 3 & 38500 & 54 & 98 & 385 \\
\hline 4 & 21000 & 30 & 250 & 385 \\
\hline 5 & 30000 & 39 & 104 & 385 \\
\hline 6 & 38500 & 44 & 64 & 385 \\
\hline 7 & 21000 & 16 & 205 & 385 \\
\hline 8 & 30000 & 25 & 78 & 385 \\
\hline 9 & 38500 & 30 & 55 & 385
\end{tabular}

Melalui hasil rekapitulasi pada SPSS 20.0 untuk pemilihan rute Jalan Tol terhadap Jalan Non Tol, didapat nilai taksiran koefisien regresi modelnya, sehingga didapatkan model utilitas sebagai berikut :

$U_{j t-j n t}=1,867-0,109\left(C_{j t}-C_{j n t}\right)+0,030\left(T_{j t}-T_{j n t}\right)$

\section{Uji Statistik Chi-Square}

Dari hasil perhitungan pada program SPSS 20.0, didapatkan nilai Chi-Square sebesar 102,995 dengan nilai signifikansi sebesar 0,000 $(<0,05)$ sehingga menolak Ho, yang menunjukkan bahwa penambahan variabel independen dapat memberikan pengaruh nyata terhadap model, atau dengan kata lain model dinyatakan fit.

\section{Uji Koefisien Determinasi}

Berdasarkan perhitungan menggunakan program SPSS 20.0, diketahui bahwa nilai Nagelkerke $R$ Square sebesar 0,287 . Nilai ini kemudia dianalogkan sehingga didapat nilai $R^{2}$ sebesar 0,58 . Sehingga diketahui bahwa presentase pengaruh variabel tarif dan waktu pada model logit ialah sebesar 58\% sedangkan $42 \%$ dijelaskan oleh variabel lain.

\section{Uji Overall Percentage}

Berdasarkan pengujian dengan Ms. Excel didapatkan hasil Overall Percentage sebesar 72,56\%. Hasil Overall Percentage pada analisis ini masuk akal dan sesuai dengan syarat statistik.

\section{Analisis Model Probabilitas Pemilihan Jalan Tol}

Dalam analisis model dengan logit binomial, berdasarkan data yang telah dianalisis sebelumnya didapat model yang berasal dari selisih utilitas antara Jalan Tol dan Jalan Non Tol. Probabilitas pemilihan Jalan Tol dapat dihitung sebagai berikut :

$$
P_{j t-j n t}=\frac{1}{1+e^{-\left(3,1005-0,185\left(C_{j t}-C_{j n \mathrm{r}}\right)+0,052\left(T_{j \mathrm{r}}-T_{j n t}\right)\right)}}
$$

(8)

Dalam analisis model dengan probit binomial, berdasarkan data yang telah dianalisis sebelumnya didapat model yang berasal dari selisih utilitas antara Jalan Tol dan Jalan Non Tol. Probabilitas pemilihan Jalan Tol dapat dihitung sebagai berikut : 


$$
P_{j t-j n t}=\varphi\left(\frac{1,867-0,109\left(C_{j t}-C_{j n t}\right)+0,030\left(C_{j t}-C_{j n t}\right)}{\sigma}\right.
$$

Dengan $\mathrm{P}_{\mathrm{jt} \text {-jnt }}=$ probabilitas jalan tol terhadap jalan non tol, $\mathrm{C}_{\mathrm{jt}}=$ besar tarif yang berlaku pada jalan tol, $\mathrm{C}_{\mathrm{jnt}}=$ besar tarif yang berlaku pada jalan non tol, $\mathrm{T}_{\mathrm{jt}}=$ waktu perjalanan yang ditempuh saat melalui jalan tol, dan $\mathrm{T}_{\mathrm{jnt}}=\mathrm{waktu}_{\mathrm{a}}$ perjalanan yang ditempuh saat melalui jalan non tol, $\phi=$ kumulatif distribusi normal, dan $\sigma=$ standar deviasi, diasumsikan $=1$

Berdasarkan perhitungan Ms. Excel, didapat probabilitas pemilihan Jalan Tol pada setiap skenario dengan Model Logit dan Probit adalah seperti pada Tabel 6 :

Tabel 6. Rekapitulasi Probabilitas Pemilihan Tiap Skenario Model Logit dan Probit

\begin{tabular}{|c|c|c|c|c|}
\hline \multirow[t]{2}{*}{ Skenario } & \multirow{2}{*}{$\begin{array}{l}\text { Selisih Tarif Tol } \\
\text { - Non Tol } \\
C_{j t}-C_{j n t}\end{array}$} & \multirow{2}{*}{$\begin{array}{c}\text { Selisih Waktu } \\
\text { Tol - Non Tol } \\
C_{j t}-C_{j n t}\end{array}$} & \multirow{2}{*}{$\begin{array}{l}\text { Hasil } \\
\text { Perhitungan } \\
\text { Probabilitas } \\
\text { Model Logit }\end{array}$} & \\
\hline & & & & Model Probit \\
\hline 1 & 21000 & 40 & 0,7858 & 0,7817 \\
\hline 2 & 30000 & 49 & 0,5257 & 0,5267 \\
\hline 3 & 38500 & 54 & 0,2298 & 0,2390 \\
\hline 4 & 21000 & 30 & 0,6857 & 0,6837 \\
\hline 5 & 30000 & 39 & 0,3972 & 0,4079 \\
\hline 6 & 38500 & 44 & 0,1507 & 0,1564 \\
\hline 7 & 21000 & 16 & 0,5130 & 0,5231 \\
\hline 8 & 30000 & 25 & 0,2414 & 0,2569 \\
\hline 9 & 38500 & 30 & 0,0789 & 0,0764 \\
\hline
\end{tabular}

Berdasarkan Tabel 6 didapat disimpulkan bahwa hasil probabilitas dengan model logit dan probit memiliki nilai yang hampir sama. Probabilitas paling tinggi terjadi pada skenario 1 dengan tarif terendah serta selisih waktu tol dan non tol besar dan probabilitas paling kecil terjadi pada skenario 9 dengan tarif tertinggi dan selisih waktu tol dan non tol kecil. Hal ini dapat disimpulkan bahwa semakin mahal tarif jalan tol maka akan semakin kecil probabilitas pemilihan jalan tol dan sebaliknya. Demikian juga dalam waktu tempuh, semakin besar perbedaan waktu jalan tol dan jalan non tol maka probabilitas pemilihan jalan tol juga akan lebih besar dan sebaliknya.

\section{hasil dan pembahasan}

Hasil probabilitas dengan model logit dan probit memiliki nilai yang hampir sama. Probabilitas paling tinggi terjadi pada skenario 1 dengan tarif terendah (Rp. 21.000) serta selisih waktu tol dan non tol lebih besar (40 menit) dan probabilitas paling kecil terjadi pada skenario 9 dengan tarif tertinggi (Rp. 38.500) dan selisih waktu tol dan non tol 
lebih kecil (30 menit). Semakin mahal tarif jalan tol maka akan semakin kecil probabilitas pemilihan jalan tol dan sebaliknya serta semakin besar perbedaan waktu jalan tol dan jalan non tol maka probabilitas pemilihan jalan tol juga akan lebih besar dan sebaliknya.

\section{DAFTAR PUSTAKA}

Ben-Akiva, M.E dan Bolduc, Denis.(1996). "Multinomial Probit with a Logit Kernel and a General Parametric Specification of The Covariance Structure”. MIT Press. Cambridge, Mass.

Ben-Akiva, M.E dan Lerman, S.R.(1985). "Discrete Choice Analysis: Theory and Application to Travel Demand". MIT Press. Cambridge, Mass.

Breidert Christoph. (2005). "Estimation of Willingness to Pay: Theory, Measurement, Application". Deutscher Universitäts-Verlag.

Greene, William H. (1997). "Econometric Analysis”. Prentice Hall. University of Michigan. New York.

Hensher, D.A. (1993). "Stated Preference Analysis of Travel Choices: The State of Practice”. Institute of Transport Studies, Graduate School of Business, University of Sydney.

Hensher, D.A., Rose, J.M. dan Greene, W.H. (2005). “Applied Choice Analysis: A Primer”. Cambridge University Press. Cambridge.

Kanafani, Adib K.(1983). "Transportation Deman Analysis". McGraw Hill. University Of Michigan. New York

Kroes, Eric P. dan Robert J Sheldon.(1988). "Stated Preference Methods: An Introduction”. Journal Of Transport Econimics and Policy.

Lestari, Fitri Catur, (2015). “Model Probit dan Logit”. Sekolah Tinggi Ilmu Statistik. Jakarta

Miro, Fidel. (2005). "Perencanaan Transportasi". Jakarta: Erlangga.

Ortuzar, Juan de Dios, dan Luis G. Willumsen.(2011). "Modelling Transport”. West Sussex: John Wiley \& Sons, Ltd.

Panjaitan, Imelda M. (2012).” Pemodelan Pemilihan Moda Angkutan Penumpang Karya Agung \& KBT (Koperasi Bintang Tapanuli) dengan ketetapan Model Probit dan Logit Studi Kasus Medan Balige”.Jurnal Universitas Sumatera Utara.

Prakoso, Rendy Wisnu. (2011). "Analisa Tarif Tol dengan Metode Stated Preference Studi Kasus Jalan Tol Jorr II Segmen Cengkareng - Kunciran”. Jurnal Universitas Indonesia

Rahardjo, Edy. (2001). "Perbandingan Model Probit dan Model Logit Dalam Menghitung Probabilitas Pilihan Menggunaka Kendaraan Pribadi dan Angkutan Umum”. Jurnal Universitas Indonesia.

Syafi'i. (2010). "Topik Khusus Perencanaan dan Pemodelan Transportasi”. http://sipil.ft.uns.ac.id/ekuliah/login/index.php. Diakses pada tanggal 28 September 2016.

Tamin, O.Z.(2000). "Perencanaan dan Pemodelan Transportasi Jilid 1".ITB Bandung.

Tim Pelaksanaan Pekerjaan ATP - WTP Tol Solo - Ngawi. (2016). "Usulan Teknis ATP WTP PT SNJ". Surakarta. 